\title{
Endoscopic retrieval of a huge gastric trichobezoar using an electrosurgical knife
}

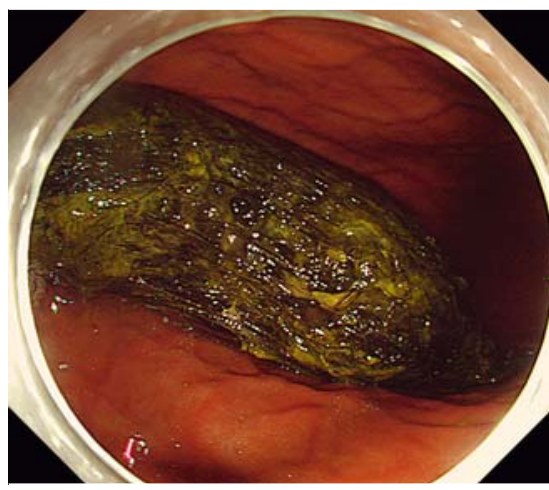

- Fig. 1 Endoscopic image showing a large gastric trichobezoar in a 22-year-old patient.

A trichobezoar is a rare type of bezoar and usually located in the stomach; however, sometimes it extends through the pylorus into the small bowel, even reaching the transverse colon [1]. Trichobezoars may cause potentially life-threatening complications, such as intestinal obstruction, gastric bleeding, and perforation. Epigastric surgical incision is the most common method of large trichobezoar removal [2]. Herein, we report a case of successful endoscopic retrieval of a trichobezoar after its fragmentation using an electrosurgical knife.

A 22-year-old woman visited the primary clinic with a history of upper abdominal pain and early satiety. She had been habitually eating her own hair since childhood. The endoscopic findings showed a large, densely packed intragastric trichobezoar (dark hair with hard mass) approximately $6 \mathrm{~cm} \times 15 \mathrm{~cm}$ in size extending through the pylorus, and a shallow ulcer in the body ( $>$ Fig. 1). We then decided to remove the trichobezoar endoscopically.

With the patient under conscious sedation with midazolam plus propofol, we used a two-channel gastroscope (GIF2TQ260M; Olympus, Tokyo, Japan) and tried to fragment and remove the trichobezoar using grasping forceps through an overtube. As the lump was huge,

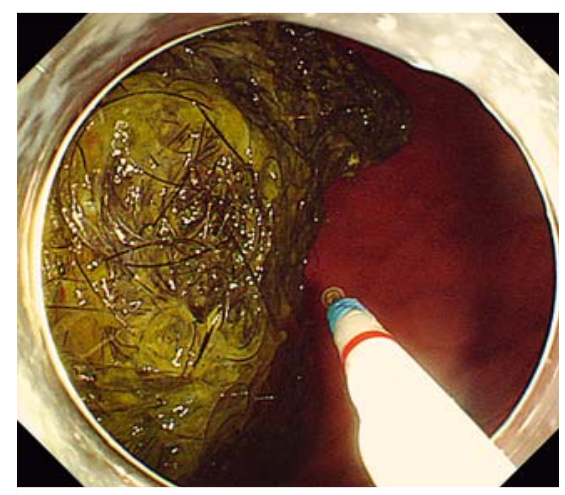

- Fig. 2 The trichobezoar was broken up using an electrosurgical knife.

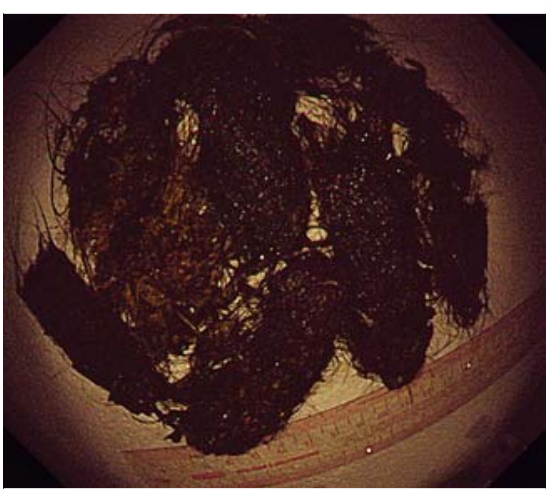

- Fig. 3 The trichobezoar completely removed after fragmentation.

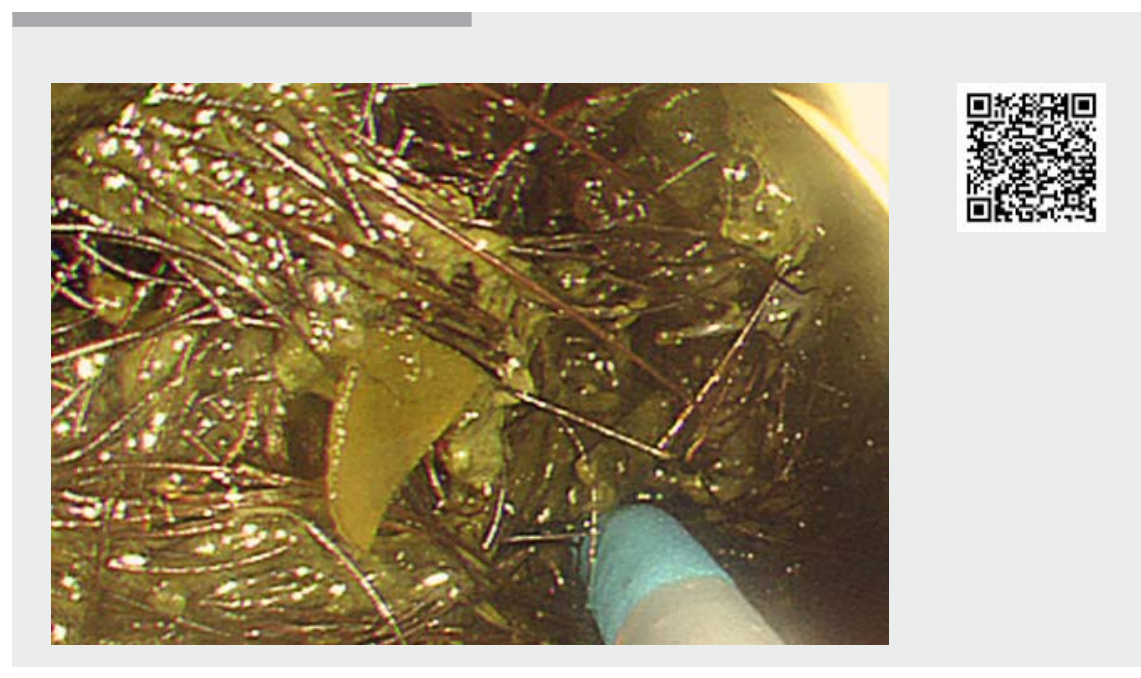

$\checkmark$ Video 1 Endoscopic retrieval of a large gastric trichobezoar after fragmentation into several pieces using an electrosurgical knife.

dense, and tangled in hair, it could not be removed even after repeated attempts. A subsequent attempt to cut the trichobezoar using argon plasma coagulation and a polypectomy snare also failed to fragment it efficiently ( Fig.2). Finally, we used an electrosurgical knife (IT knife 1; Olympus, Tokyo, Japan) to cut the trichobezoar effectively into two pieces ( $\triangleright$ Video 1 ). The smaller piece was further fragmented and then successfully removed using grasping forceps ( $\triangleright$ Video 1 ). The remaining piece was successfully removed in two sessions; each session took about an hour ( $\triangleright$ Fig.3). The clinical course was tolerable. After trichobezoar removal, the patient was free of pain; she was given a regular diet and discharged.

Endoscopy_UCTN_Code_TTT_1AO_2AL

\section{Competing interests}

The authors declare that they have no conflict of interest. 
The authors

Seung Gyun Baek ${ }^{1}$, Chi Hyuk Oh' ${ }^{1}$, Ga Young Shin ${ }^{2}$, Jung-Wook Kim', Jae-Young Jang ${ }^{1}$

1 Division of Gastroenterology and Hepatology, Department of Internal Medicine, Kyung Hee University Hospital, Kyung Hee University School of Medicine, Seoul, Republic of Korea

2 Department of Medicine, Graduate School, Kyung Hee University, Seoul, Republic of Korea

Corresponding author

\section{Chi Hyuk Oh, MD}

Division of Gastroenterology and Hepatology, Department of Internal Medicine, Kyung Hee University Hospital, 23 Kyungheedae-ro, Dongdaemun-gu, Seoul 02447, Republic of Korea Fax: +82-2-9681848

ochihyuk@gmail.com

\section{References}

[1] Vaughan ED Jr, Sawyers JL, Scott HW Jr. The Rapunzel syndrome. An unusual complication of intestinal bezoar. Surgery 1968; 63: 339-343

[2] Benatta MA. Endoscopic retrieval of gastric trichobezoar after fragmentation with electrocautery using polypectomy snare and argon plasma coagulation in a pediatric patient. Gastroenterol Rep (Oxf) 2016; 4: 251 253

\section{Bibliography}

Endoscopy 2021; 53: E357-E358

DOI 10.1055/a-1293-6677

ISSN 0013-726X

published online 19.11.2020

(c) 2020. Thieme. All rights reserved.

Georg Thieme Verlag KG, Rüdigerstraße 14,

70469 Stuttgart, Germany

\section{ENDOSCOPY E-VIDEOS}

https://eref.thieme.de/e-videos

回回 Endoscopy E-Videos is a free access online section, reporting 田: on interesting cases and new techniques in gastroenterological endoscopy. All papers include a high quality video and all contributions are freely accessible online.

This section has its own submission website at

https://mc.manuscriptcentral.com/e-videos 